\title{
Th. W. Adorno: filosofía frente a la catástrofe
}

Th. W. Adorno: Philosophy in the Face of Catastrophe

José A. Zamora

Instituto de Filosofía, CSIC

\section{RESUMEN}

El pensamiento de Th. W. Adorno y su contribución a la teoría crítica de la sociedad tiene su núcleo central en la confrontación con la barbarie y en la reflexión teórica sobre las condiciones sociales que la hacen posible. 50 años después de su muerte su propuesta de crítica radical sigue dando que pensar y ofreciendo claves con las que enfrentarse a la crisis del presente.

PALABRAS ClAVE: Th. W. Adorno, Teoría Crítica, sufrimiento social, capitalismo, barbarie

\section{ABSTRACT}

The thought of Th. W. Adorno and his contribution to the critical theory of society has its central nucleus in the confrontation with barbarism and in the theoretical reflection on the social conditions that make it possible. Fifty years after his death, his proposal of a radical critique continues giving to think and keys with which to confront the crisis of the present.

KEY WORDS: Th. W. Adorno, Critical Theory, social suffering, capitalism, barbarism 
"España no fue realmente un tema para Adorno" (Tiedemann 2007: 141). Así se expresaba el editor de los escritos de Adorno, Rolf Tiedemann, en la clausura del congreso "El pensamiento de Th. W. Adorno: balance y perspectivas" celebrado en la Universitat de les Illes Balears en Palma (Mallorca) el 3 de mayo de 2006 (Cabot 2007). Con ello venía a decir que lo que nos permite acceder a la obra de Adorno no son supuestos intereses regionales. "Adorno y España" no es un tema que ofrezca interés ni dé para mucho. Con todo, es posible establecer una conexión que no es marginal. En esa misma ocasión, Tiedemann no dudó en señalar al fascismo como una realidad que vincula negativamente la historia de España y Alemania. Y esto no es un dato menor, si tenemos en cuenta que el pensamiento y la vida de Adorno se despliegan en la permanente conciencia de la presencia de la barbarie. La inevitable confrontación con el fascismo fue "el motor real, directo y en mayor medida indirecto de su filosofía" (Tiedemann 2007: 143), recordó R. Tiedemann a la audiencia en su conferencia. Y, por qué no decirlo, lo que Adorno pensó y expresó sobre este tema tiene un significado inmediato para quienes somos miembros de una sociedad que, como la española, ha estado y está fuertemente influenciada por el fascismo o, si se prefiere, por el autoritarismo.

En este país no son pocos a los que seguramente disgusta que se les recuerde este dato. Tampoco son pocos los que se resisten a reconocer la persistencia y la presencia de la barbarie. La lógica del progreso y de la superación está demasiado enraizada en los patrones sociales de percepción y pensamiento. Y, sin embargo, al menos ochenta y ocho mil víctimas de crímenes de guerra y de la violencia sistemática de represalias del régimen de Franco inmediatamente después de la guerra siguen enterradas en fosas comunes y se consideran desaparecidas. España es el segundo país del mundo, después de Camboya, en cuanto al número de personas desaparecidas cuyos restos no se han encontrado o identificado. El

${ }^{1}$ Esta contribución sobre el pensamiento de Th. W. Adorno 50 años después de su fallecimiento está dedicada al que fue so editor, Rolf Tidemann, que nos dejó hace casi dos años. Su contribución al acceso a la obra completa de Adorno posee un valor extraordinario, también sus aportaciones a la interpretación de su pensamiento. Por ello lo tomaré de acompañante privilegiado en este breve recorrido por lo que constituye el hijo rojo de su filosofía. Citaré la edición de las Obras de Th. W. Adorno de la editorial Akal, pero modificaré la traducción allí donde sea conveniente. 
Estado y el poder judicial nunca han tomado medidas serias y eficaces para contrarrestar esta realidad. Tras la muerte de Franco, las víctimas de la guerra y de la dictadura no debían obstaculizar la "reconciliación" y la "modernización" del país. Lo que se interpretó oficialmente como un signo de la generosidad de los perdedores de la guerra civil y de los perseguidos y represaliados de la dictadura fue, de hecho, un olvido o un silencio impuesto por sus herederos y por los beneficiarios de las nuevas circunstancias. Recordar los horrores del pasado se consideraba resentimiento y negación del futuro y estaba mal visto. La mayoría de los ciudadanos anhelaba la prosperidad y la democracia, en ese orden, y esto requería que todas las fuerzas se concentraran en la producción y el consumo, cuyo acompañamiento orquestal no podía ser otro que el optimismo amnésico. La mirada se dirigió hacia un futuro esperanzador convertido en meta común con todos los apoyos. La llamada democratización se cargó con grandes y legítimas expectativas. Pero la lealtad de los ciudadanos se basaba sobre todo en la esperanza de modernización, que a su vez se apoyaba en una promesa de prosperidad, que cerraba los ojos a sus condiciones sociales o ecológicas de posibilidad. Apartar la vista de las continuidades, por tanto, se convirtió rápidamente en la actitud social y política de la mayoría. Los millones de "nuevos demócratas" se liberaron de repente de las cargas hereditarias. La sustitución del lema de confrontación política "ruptura" por el lema electoral "cambio" sirvió para establecer el punto medio y, por tanto, el "centro" como punto de referencia social, económico y político para el conjunto de la sociedad, y todo ello sin grandes costes, es decir, sin cuestionar la modernización autoritaria del país bajo el franquismo y sin problematizar su continuación por otros medios, por no hablar de la renuncia a afrontar la conexión entre la crisis del capitalismo liberal en las primeras décadas del siglo XX y la guerra civil/dictadura como punto de partida para una transformación más profunda de las estructuras sociales. Tampoco se abordó el sufrimiento social producido por esa modernización autoritaria en los años sesenta y setenta. Más bien al contrario, las víctimas y el sufrimiento del pasado fueron percibidos como "precio necesario" del desarrollo y el futuro democráticos (Zamora et al., 2016).

Sin embargo, esta cuestión no debe considerarse de manera aislada. Está relacionada con la forma en que se entendió y se llevó a cabo la modernización del país también después de la dictadura. La intención proclamada tras la transición de transformar el rostro del país en unos pocos decenios debe tomarse al pie de la letra, porque el objetivo era transformar la apariencia más que las estructuras económicas y sociales profundas. Durante la dictadura de Franco, prevaleció un tipo de capitalismo autoritario, en el que el vínculo interno entre 
capitalismo y autoritarismo pudo desplegarse sin apenas obstáculos. Sin embargo, después de la dictadura, no se buscó en absoluto sacudirse la muda coacción de las estructuras, sino simplemente reorganizar esa coacción de forma "democrática". Hoy en día, la impía alianza entre capitalismo autoritario y nacionalismo populista está de nuevo a la orden del día. Así pues, la llamada "transición" democrática en España encaja perfectamente con el famoso dicho de Adorno en su ensayo "¿Qué significa elaborar el pasado?": "Considero que la pervivencia del nacionalsocialismo en la democracia es potencialmente más amenazadora que la pervivencia de tendencias fascistas contra la democracia" (Adorno 1959: 489). La continuidad de las condiciones de posibilidad de la barbarie es el punto crucial alrededor del cual debe girar una teoría crítica del presente. Adorno vio esa continuación de la barbarie también en la pervivencia de las condiciones que hacen posible la recaída una y otra vez: "La presión social sigue pesando mucho" -dice en "Educar después de Auschwitz"- "a pesar de toda la invisibilidad" (Adorno 1967: 599). Adorno nunca se hizo ilusiones sobre la posibilidad de una nueva recaída, que hoy se convierte en amenaza real en toda Europa.

Sin embargo, al explicitar esta conexión, no intento equiparar la catástrofe de Auschwitz con la barbarie de la dictadura de Franco, y menos aún con el período "democrático" que le siguió. Y, sin embargo, toda clase de barbarie coloca al pensamiento ante aquello que se resiste a su poder de interpretación: el sufrimiento de las víctimas. El auténtico núcleo temporal de la teoría está, como dice Tiedemann, contenido en los "gritos de las víctimas" (2009:24). Y el primer requisito de la filosofía es ayudar a expresar su sufrimiento. El mandamiento perenne de "seguir viviendo", de "continuar" o de "reconstruir", que reduce estos sufrimientos a precio necesario, en realidad significa entregar los muertos y desaparecidos al olvido para a continuación abdicar más pronto que tarde frente a los sufrimientos actuales. Así se sigue reproduciendo aquella frialdad sin la cual -según Adorno- "Auschwitz no habría sido posible" (Adorno 1966a: 332). En esa frialdad podemos reconocer la forma de socialización en la que se fundamenta la barbarie (cf. Maiso 2016). La frialdad "se debe al principio de autoconservación volcada sobre sí, la contrapartida de la destrucción por la destrucción" (Tiedemann 2009:33). Por eso las formas de socialización y los diferentes tipos de barbarie son como vasos comunicantes. Revelan conexiones allí donde la mayoría de la gente sólo puede ver peculiaridades históricas, culturales o políticas. En mi opinión, el juicio equivocado sobre esta realidad es una de las razones más importantes de que la centralidad de Auschwitz en el pensamiento de Adorno se convirtiera en un obstáculo para una adecuada recepción de su 
obra en España. Auschwitz fue degradado a una peculiaridad alemana que habría llevado a la filosofía de Adorno a un callejón sin salida, como se podía escuchar por doquier en nuestro país imitando el veredicto de Habermas. Hubo que esperar hasta mediados del década de 1990 para que se produjera una recepción significativa de Adorno que daba cuenta de la centralidad de Auschwitz en su pensamiento, y no en forma de una contextualización relativizadora. Esta nueva recepción no consideraba el índice temporal "después de Auschwitz" como un signo de inactualidad, sino como la clave de su filosofía y su teoría de la sociedad (cf. Claussen 1988; Zamora 2004). La mayoría de estas nuevas lecturas tomaron distancia de las interpretaciones que seguían el cambio de paradigma habermasiano e intentaron recuperar la actualidad de la autocrítica radical de la modernidad, la relación entre pensamiento y negatividad, la crítica radical del capitalismo o la constitución anamnética de la razón que caracterizan el pensamiento de Th. W. Adorno (cf. Maiso 2010; Cabot 1997; Gómez 1998). ${ }^{2}$

No obstante, es cierto que los espíritus contemporáneos tienen enormes dificultades con la insistencia de Adorno en pensar la negatividad de lo existente o al menos en dar razón de su incomprensibilidad. La lectura de los textos de Adorno genera grandes reservas intelectuales en bastantes de ellos. Especialmente entre aquellos que están ansiosos por ver el mundo desde una perspectiva más positiva, aunque los hechos se nieguen obstinadamente a confirmarla. La condena de esta insistencia en la negatividad se ha convertido en un lugar común entre nosotros. A menudo es difamada como un confortable acomodarse en el Gran Hotel "Abismo". Pero aquellos que hoy día usan la metáfora de Lukács dedicada a Adorno están lejos de compartir su crítica de las relaciones sociales capitalistas. Se han establecido gustosamente en el Grand Hotel de la maquinaria cultural y sólo se esfuerzan por dar lustre a su nuevo nombre: Grand Hotel "No hay alternativa". En cualquier caso, ya no tiene sentido quejarse, porque la queja no sólo molesta a los privilegiados entregados al disfrute, sino que también provoca resistencia entre los que tienen que soportar el peso de la negatividad y huir de ella, aunque sea por un momento, en visiones más agradables, o que desean por lo menos no verse confrontados con la verdad de lo que les aplasta. En todo caso, quien quiera sobrevivir en el cultural business no debe llamar a las cosas por su nombre. Seguramente, pocos de esos críticos de hoy conocen la reacción de Adorno a la "broma" de Lukács en el nuevo "Prefacio" a su Teoría de la Novela. En una nota escita a finales de marzo de 1969, poco antes de su muerte, podemos leer:

${ }^{2}$ Para un análisis más detallado de la recepción de Adorno en España, cf. Zamora 2011. 
Lukács me acusó con una broma estúpida (una estupidez que hoy en día pertenece a la regresión general que se tiene por revolucionaria), que me he instalado en un hotel de lujo al borde del abismo. Esto debe ser registrado; la cabaña de la Fiebre del oro de Chaplin no sería la peor alegoría para mis pensamientos. Lukács se ha precipitado al abismo y lo considera erróneamente la salvación; no solo se encuentra ahí, sino que se arrastra hacia el fondo envejecido y achacoso como una de las figuras de Beckett que tanto le indignaban. ¿Dónde voy a vivir? ¿En el hedor de la seguridad? Prefiero vivir en mi lujoso y tambaleante hotel. Aunque su lujo no consiste en otra cosa que en la felicidad de expresar la negatividad extrema; y eso es lo que está mal visto (Adorno 2003: 36).

De lo que se trataba entonces y sigue tratándose hoy es de la difamación de la denuncia sin concesiones de la negatividad de lo existente que va de la mano de la afirmación de lo establecido, ya sea estalinista o (neo)liberal, algo ante lo que Adorno no estaba dispuesto a inclinarse. Me atrevo a aconsejar a los críticos del supuesto negativismo elitista de Adorno que lean el aforismo "Medias tintas" en Minima Moralia. Allí dice: "La evidencia de la calamidad favorece su apología: puesto que todos lo saben, nadie tiene derecho a decirlo; y, así, al amparo del silencio puede seguir su curso sin ser cuestionada" (Adorno 1951: 242).

Parece como si Thomas Mann estuviera dando expresión al sentir de estos espíritus contemporáneos cuando, después de leer la monografía de Adorno sobre Wagner, le reclamaba: " $\mathrm{S}$ i al menos hubiera alguna vez en usted una palabra positiva, estimado, que ofreciera una visión aproximada de la verdadera sociedad a postular! Las reflexiones desde de la vida dañada dejan sentir la falta de eso, sólo de eso: ¿Qué es, qué sería lo correcto?” (Adorno/Mann 2002: 122). La respuesta de Adorno a la queja de Thomas Mann nos muestra su espíritu indomable y su honestidad intelectual. Su obstinada resistencia a cualquier afirmación directa de lo positivo, le contesta, no es el resultado de una oscura disposición de carácter, que en su caso tiende más a dar rienda suelta a la expresión de la esperanza que a otra cosa, sino más bien el resultado de un ascetismo comprometido con su realización. Adorno permaneció fiel a esta convicción durante toda su vida. Siempre consideró que el hecho de no detenerse en lo negativo, pasando demasiado rápidamente a la afirmación de lo positivo, más bien favorece el mantenimiento de lo falso, en lugar de contribuir a superarlo. Sin embargo, como R. Tiedemann informa en sus recuerdos sobre una discusión entre Wolfgang Lefèvre y Adorno, este no se entregó nunca a la resignación, nunca perdió la esperanza en la realización del socialismo. Pero el 
suyo era un sí, añade Tiedemann, "a la esperanza en la realización de la utopía, de la que a la vez sabía que, desde hacía mucho tiempo, al menos desde Auschwitz, seguía haciéndose esperar" (Tiedemann 2011: 16).

De ahí la necesidad de unir el pensamiento y la crítica, algo que Adorno compartía con la mejor tradición de la Ilustración, aunque esa unión hubiera perdido en él el nexo con aquel optimismo histórico que se prometía del mero uso no tutelado de la razón el logro de la emancipación, como si este uso sólo necesitara oponerse a los viejos poderes abiertamente opresivos y derrocarlos de su trono para transformarse en la puerta del paraíso. Adorno ya no poseía una convicción tan segura como ingenua, y sin embargo no veía otra salida a lo existente y a su terca negatividad que una crítica igual de terca, que debía seguir siendo consciente de su precariedad, su insuficiencia, su frecuente neutralización e integración. Sólo la dialéctica puede hacerse cargo de esta tensión.

Existe una antología de textos de Th. W. Adorno que lleva por título una inquietante pregunta: "Si es posible seguir viviendo después de Auschwitz" (1997). La imposibilidad de dar una respuesta contundente a esta pregunta coloca a la filosofía ante su propia imposibilidad como punto de partida inevitable (Tiedemann 1997: 12). Esta antología, editada por Rolf Tiedemann en forma de reader, contiene aquellos textos que caracterizan su filosofía como una filosofía frente a la catástrofe. El lector es conducido a lo esencial de un pensamiento elaborado desde la vida dañada, ya sea en las reflexiones micrológicas sobre esa vida, ya sea en las reflexiones sobre el mundo administrado o sobre el pensamiento reificado o en las confrontaciones estéticas y metafísicas con la experiencia del sufrimiento. El estudio introductorio de Tiedemann a ese volumen nos conduce sin distracciones ni evasivas hasta el núcleo incandescente del pensamiento de Adorno. Es un pensamiento articulado y desplegado en todo momento en confrontación con la catástrofe de Auschwitz. No es que Adorno hiciera de esta catástrofe un tema, un asunto entre otros. En su obra, las referencias explícitas a Auschwitz no son tan numerosas, pero todo en ella está escrito con la conciencia de la ruptura del proceso histórico que significó dicha catástrofe. A pesar de eso, en su obra, el sufrimiento no está ontologizado como si fuera una determinación esencial de la historia, de la que lógicamente esta no podría liberarse. Lo que Adorno propone es más bien un cambio de perspectiva en el sentido de Walter Benjamin, a quien la tradición de los oprimidos le enseñó que "el 'estado de excepción' en el que vivimos es la regla" (Benjamin 1991: 697). Se trata de la perspectiva de los derrotados y los vencidos, que nos muestra un rostro de la realidad completamente diferente al hegemónico, como Adorno señala apoyándose en Kafka: 
En la Edad media, la tortura y la pena de muerte se ejecutaban en los judíos boca abajo; ya en un célebre pasaje de Tácito se critica su religión por 'invertida'. A los delincuentes se les colgaba con la cabeza hacia abajo. El agrimensor de Kafka fotografía la superficie de la Tierra tal como estas víctimas tuvieron que verla durante las inacabables horas de su agonía" (Adorno 1953: 248-249).

Cada víctima es como el negativo de la coacción persistente y, por tanto, la negación de que haya existido realmente progreso. Lo contrario sería integrar y superar hegelianamente las víctimas en el movimiento del todo hacia un final feliz, degradándolas a estaciones paso de la ascensión imparable del espíritu o del género humano, y convertir de ese modo sus sufrimientos en una quantité négliegeable que inevitablemente hay que pagar como precio de ese ascenso. Esto podrá contribuir a la justificación de la (falsa) totalidad, pero desde luego no a hacer justicia a las víctimas, pues desde su perspectiva toda víctima es una víctima de más. Mientras que la perspectiva que parte de la totalidad considera el sufrimiento como una excepción y tiende casi inevitablemente a establecer una cuenta con más y menos, positivo y negativo, por muy refinada y especulativamente que dicha cuenta se formule, la perspectiva de las víctimas desmiente el carácter de excepción del sufrimiento, pues para ellas, el estado de excepción es la regla. Para quien es aniquilado, la negatividad aniquiladora no puede ser relativizada, no puede ser reducida a momento, a aspecto. Para él o ella la negatividad es total, porque la aniquilación es total. Detrás de la afirmación explícita o del supuesto implícito del carácter de excepción/accidente de lo negativo se oculta una relativización inadmisible del sufrimiento y con ella su sanción. Por ello, sólo se puede hacer justicia a las dimensiones reales de la negatividad que se manifiesta en Auschwitz por medio de la exageración, ya que, más peligroso que exagerar, es trivializar lo negativo.

El gesto de exageración se opone al principio de realidad para expresar lo que a este se le escapa. Su sesgo quiere llamar la atención sobre la unilateralidad dominante y, por tanto, ya no percibida, que pasa por alto el horror actual. En palabras de Adorno: "La astilla en tu ojo es la mejor lente de aumento" (Adorno 1951: 55). Si cada reconstrucción de la historia es una anamnesis del proceso anterior, las reconstrucciones que han prevalecido hasta ahora y que se encontraban bajo el hechizo del progreso, muestran una extraña complicidad con la amnesia. Sin embargo, no son casuales o arbitrarias, están determinadas por la forma en que el proceso histórico ha tenido lugar realmente. Porque el crimen real perpetrado contra las víctimas y su olvido están íntimamente relacionados. De modo que, para no hacer desaparecer el sufrimiento actual, que 
en Auschwitz alcanzó cotas insospechadas, en una interpretación global de la histórica, es necesario mirar toda la historia y la sociedad desde este punto de vista. Lo singular obliga a un cambio de perspectiva sobre el todo, haciendo percibir el lado oculto de la historia: "los martirios y humillaciones jamás experimentados antes de los que fueron deportados en vagones para el ganado arrojan una intensa y mortal luz sobre el más remoto pasado" (Adorno 1951: 244).

Auschwitz nos obliga a mirar y pensar la sociedad, la historia, la cultura, el destino y la vida del individuo desde su perspectiva. En otras palabras, nuestra mirada se dirige a lo que permanece en todos ellos de las condiciones que hicieron posible ese genocidio y que contribuyen a su posible repetición. Esta catástrofe carga el pensamiento con una culpabilidad que es difícil de explicar a quienes piensan que lo que ocurrió en Auschwitz no les incumbe directamente, una culpabilidad que está determinada por la convicción de que existe una complicidad entre el pensamiento y los procesos históricos que hicieron posible Auschwitz. Esta culpabilidad lleva a una responsabilidad ineludible con las víctimas, las víctimas del genocidio y todas las demás víctimas. El pensamiento de Adorno está guiado, por tanto, por un sentimiento de vergüenza ante las víctimas, por un sentimiento de dolor indisoluble y una esperanza que paradójicamente viene exigida por ese dolor, que, como dijo su amigo Benjamín, es una esperanza que nos es dada solo por mor de los que carecen de ella.

Existen dos pasajes centrales de la Dialéctica Negativa y la Teoría Estética relativos a la vergüenza (Tiedemann 2006: 38). El primero se refiere a la visión de Georg Simmel sobre lo poco que se le nota a la historia de la filosofía el sufrimiento de la humanidad. La vergüenza es una razón de peso para no suprimir esta percepción (Adorno 1966a 149). El segundo pasaje se refiere a la poesía de Paul Celan, en la que se pone de manifiesto la vergüenza del arte ante el sufrimiento que escapa a la experiencia y a su sublimación (Adorno 1970: 426). Ambas citas llevan a Tiedemann a caracterizar la vergüenza de Adorno de la siguiente manera:

La vergüenza de la que hablaba Adorno es la del que escapó, del que, como nunca se cansó de subrayar, había escapado accidental e injustamente, que necesariamente tenía que fracasar en sus esfuerzos por comprender lo que había sucedido, por no hablar de extraerle cualquier 'sentido', alguien al que sólo le había quedado la vergüenza como un mínimo moral (Tiedemann 2006: 38). 
Un pensamiento para el que el sufrimiento se ha vuelto algo ajeno y cuya expresión no constituye el criterio de verdad por excelencia, es decir, que no tiene su telos en la abolición del sufrimiento producido socialmente, se convierte más pronto que tarde en la "música de acompañamiento" disimuladora, compensadora o legitimadora de las relaciones sociales. Ante la exigencia de no sucumbir a esta ruina del pensamiento, Adorno propone un nuevo imperativo categórico - pensar y actuar de tal manera que Auschwitz no se repita- cuya relevancia sólo puede ser negada con una dosis inasumible de cinismo. Este imperativo, lejos de transformarnos en estatuas de sal cautivas del pasado, quiere más bien movilizar la memoria solidaria de las víctimas, el recuerdo de las esperanzas no cumplidas y de las injusticias pendientes, contra todo lo que sigue generando dolor y sufrimiento y destruyendo a los individuos. El nuevo imperativo está referido a los desastres del presente, al horror perenne. Aborda críticamente las causas de la barbarie y su persistencia. El sufrimiento acumulado en la historia no permite la ignorancia o la aprobación. Que ambos continúen reproduciéndose es parte de la propia barbarie. Por eso el imperativo de Adorno va acompañado de una conciencia insobornable de la persistencia de las condiciones que hicieron posible Auschwitz.

Auschwitz ha rasgado definitivamente el velo de optimismo que cubría las contradicciones del proceso emancipador moderno. Las promesas de autonomía y justicia dadas a la humanidad por la Ilustración no se han hecho añicos por el ataque de fuerzas atávicas o la resistencia recalcitrante de las potencias pasadas. La adopción de una explicación de este tipo sólo aumentaría la indefensión frete la barbarie actual. Auschwitz nos obliga a llegar al fondo de la dialéctica de la Ilustración, la dialéctica del progreso y la regresión, el entrelazamiento de la razón dominante con el principio de dominación mismo. Esta obligación tiene su origen en la convicción de la necesidad de dar cumplimiento a las promesas de la Ilustración, pero también en el hecho de que la mayor catástrofe del siglo XX en Europa revela una constitución perversa de la sociedad y del individuo de tal magnitud que exige una crítica asimismo radical de la racionalidad que la sustenta. Es necesario cambiar fundamentalmente las relaciones de los individuos con su propia naturaleza interna y de la sociedad con la naturaleza que da soporte a su reproducción, así como las relaciones sociales, si se quiere detener "la marcha de la humanidad hacia la inhumanidad" (Adorno 1965: 12).

Esto tiene una lectura de teoría social que conecta a Adorno con la crítica de la economía política de Marx. Todos los individuos dependen de una organización social que les precede y que tiene por objeto garantizar su autoconservación mediante la división del trabajo y los mecanismos de producción y distribución. 
La sociedad se convierte en un todo (negativo) sólo a través del antagonismo y de la autonomización de las relaciones sociales reificadas frente a los individuos que las producen. La organización capitalista de las relaciones sociales, que supuestamente está orientada a la autoconservación de sus miembros, subordina la autoconservación al aumento y la acumulación del valor abstracto y la vincula a la reproducción de las relaciones de dominación que lo hacen posible y que no pueden atribuirse meramente a la necesaria división del trabajo. El resultado de esta subordinación es una inversión del fin (autoconservación de los individuos y eliminación del sufrimiento evitable) y de los medios (organización social), que dejan de este modo de ser realmente medios para convertirse en fines. La autoconservación mediada por las relaciones de poder se transforma en un medio de aumento y acumulación de valor abstracto. En el capitalismo, por lo tanto, se produce una inversión: la revalorización del capital se convierte en la finalidad de la producción y la distribución de bienes y servicios, porque este mecanismo abstracto -afirma la economía política liberal- es la forma más eficiente y segura de asegurar la autoconservación de los individuos y la reproducción de la sociedad. Pero, de hecho, las personas juramentadas con la pura lucha por la autoconservación a la que los condena la revalorización del capital ven frustrada justo aquella autonomía que les permitiría perseguir realmente objetivos más allá de la mera autoconservación.

La condición de la posibilidad de una crítica inmanente de esta totalidad negativa, es decir, de la falsa identificación de lo universal y lo particular, se da en el sufrimiento, ya que "la sociedad se puede sentir de modo inmediato allí donde duele" (Adorno 1996: 55). El sufrimiento generado socialmente es el signo de que la totalidad social se impone ciegamente a los sujetos individuales. "La identidad de sociedad e individuo, en la forma en que se abre paso, es lo negativo consumado: así la experimenta el individuo a través de un dolor físico y un padecimiento psicológico llevados al extremo" (Adorno 1966b: 84). La coacción sobre el individuo que se revela en el sufrimiento es la prueba de la particularidad de la dominante universalidad social abstracta, que solo puede ser desentrañada por una teoría de la sociedad crítica. "La teoría y la experiencia intelectual precisan de su interacción. La primera no contiene respuestas para todo, sino que reacciona a un mundo falso hasta en lo más íntimo" (1966a 39-40).

El punto de intersección entre la objetividad antagónica y la experiencia individual es el sufrimiento, "objetividad que pesa sobre el sujeto". Lo que este "experimenta como lo más subjetivo suyo, su expresión, está mediado objetivamente" (Adorno 1966a, 28). De ahí que para Th. W. Adorno los dos polos, experiencia individual y teoría crítica de la sociedad, se reclamen 
mutuamente, sin que desaparezca la tensión entre ambos y sin que ninguno de los dos polos pueda prescindir del otro en ningún momento (Adorno 1968, 173). La teoría que pretende ser autoconciencia crítica de unas relaciones sociales cosificadas y casi blindadas frente a su cuestionamiento teórico y práctico, tiene que alimentarse de la experiencia subjetiva. Pero dicha experiencia necesita de esa misma teoría, si es que ha de llegar a ser una experiencia no recortada ni reglamentada. Esto es posible porque se trata de una experiencia que se desarrolla a partir de su objeto en cuanto objeto contradictorio y dinámico y que, precisamente por eso, no es puramente subjetiva e insustancial: recoge en sí toda la carga de la objetividad que la atraviesa y, en cuanto mediada por la racionalidad que la informa, posibilita su abordaje teórico, el trabajo del concepto. Adorno nunca consideró cancelada la posibilidad, por muy debilitada que fuera, de experimentar como tal la coacción que sufren los individuos en una sociedad marcada por la tendencia a la socialización total. Asimismo, nunca dejó de confiar en la posibilidad de que el contenido de esa experiencia pudiera emerger en la interpretación de los fenómenos sociales y culturales. Y sobre ese contenido es sobre el que debía volcarse la teoría de la objetividad social (Meyer 2005: 132ss).

Sin embargo, su programa de teoría social crítica, tempranamente formulado en la lección inaugural "Actualidad de la filosofía" (1931), no pretendía un conocimiento capaz de abarcar la totalidad social gracias a la fuerza del espíritu, sino que más bien buscaba penetrar en los fenómenos singulares y, de manera inmanente, con el apoyo de una dialéctica materialista, no solo mostrar en ellos la totalidad antagonista, sino hacer saltar por los aires el conjunto de lo meramente dado (Adorno 1931, 314). La "sociedad" debe hacerse legible en los fenómenos históricos singulares por medio del examen de la génesis de lo inmediatamente dado, de lo petrificado como "segunda naturaleza", pero en realidad devenido históricamente y constituido socialmente. En esto consiste, según Th. W. Adorno, el procedimiento de K. Marx en su crítica de las formaciones sociales capitalistas (Adorno 1964/1965: 190). La mediación social se manifiesta y es identificable en lo mediado, en los individuos singulares, en las situaciones e instituciones concretas. Asimismo, solo a través de la explicitación de la mediación que los constituye sin subsumirlos completamente es posible hacer justicia a su concreción y cuestionar una identidad coagulada que niega cualquier trascendencia de lo fáctico (Adorno 1965: 10). La filosofía social interpretativa en cuanto dialéctica negativa no procede more hegeliano, sino que saca a la luz el carácter mediado de lo concreto por medio del despliegue de la constelación de fenómenos empíricos en la que se encuentra, colocándolo en una 
trama de interrelaciones con otros fenómenos y movilizando un conjunto de diferentes perspectivas interpretativas fundamentalmente provenientes de la psicología social psicoanalítica, de la sociología, de la teoría de la cultura y de la crítica de la economía política. Dichas perspectivas no poseen un carácter cerrado y acabado, no son corpus doctrinales estancos, no son explicaciones totales; más bien están sometidas a un triple proceso de transformación debido a su dinámica de desarrollo interno, a su confrontación con una realidad histórica, ella misma dinámica y cambiante, y a las tensiones productivas entre las diferentes perspectivas teóricas, irreductibles entre sí (Adorno 1955; Heitmann 2016/2017, 56ss). Con todo, este entramado teórico encuentra en la crítica de la economía política y, específicamente, en la crítica de la forma mercancía, la clave fundamental de interpretación de los fenómenos concretos que actúa como punto focal del trabajo teórico.

Este planteamiento de Adorno contrasta con la línea de recepción de la Teoría Crítica hoy hegemónica. Esta se ha volcado de manera preferente, cuando no exclusiva, en debates teóricos alejados de las confrontaciones sociales y las verdaderas crisis del presente. Resulta llamativa la creciente integración de la Teoría Crítica en la maquinaria académica normalizada. Sin embargo, su desempeño no se decide hoy en razón de la posición que se adopte frente Jürgen Habermas, Axel Honneth o Rainer Forst, por nombrar las figuras actuales más reconocibles. Más bien se mide por su objeto y por cómo se reflexione sobre las relaciones de dominación en cada momento y en cada situación. La actualización de la Teoría Crítica tiene que proceder de una confrontación rigurosa con su objeto, frente al cual los desarrollos teóricos dan o no la talla. El propio A. Honneth constata una tendencia a alejarse de la realidad social para volcar la reflexión exclusivamente sobre las condiciones teóricas y prácticas de posibilidad de la crítica. Una parte no despreciable del trabajo teórico se dedica a la clasificación casi administrativa de las variantes de la crítica. La división más extendida es la que se establece entre crítica interna y externa, sobre la que se construyen nuevas divisiones (Jaeggi 2014: 216ss.; Romero/Zamora 2020). En este marco clasificatorio suelen ganar la partida las concepciones normativas y con ellas los esfuerzos por mostrar y fundamentar los criterios normativos de la crítica. La contribución de estas discusiones a la comprensión concreta de los procesos sociales se reduce de tal modo, que amenaza con provocar una pérdida del objeto propio de la Teoría Crítica. Cabe preguntarse qué queda aquí del impulso crítico que debe animarla. No puede negarse que existe un peligro de que los fenómenos, los procesos, las estructuras o las experiencias que constituyen el meollo de la realidad social se vean degradados a ejemplos a través 
de los que mostrar la plausibilidad de los diferentes modelos de crítica. Honneth reconoce ese peligro de "construir por medio de una inmersión idealista principios de justica que se muestran inconsistentes frente a una realidad indócil" (2011: 119).

Frente a esta deriva, creo que la actualidad de la Teoría Crítica de Th. W. Adorno se decide en su capacidad para dar cuenta de los procesos de crisis socioecológica que hoy se han convertido en una amenaza de completa aniquilación y que condenan a millones de seres humanos a ser población sobrante. La Teoría Crítica solo puede existir en el modo de una crítica materialista que mantiene abierta la posibilidad de una superación de la relación social que en la estela de Marx llamamos "capital". La formación de la teoría no es un fin en sí; ella solo se desarrolla ante el horizonte de la supresión y la superación del objeto de su crítica, y apunta por tanto a su propia cancelación en cuanto ontología negativa del presente. Todavía hoy sigue lamentablemente vigente la respuesta de Adorno a la pregunta por la meta de la sociedad emancipada: "sería únicamente lo más burdo: que nadie tenga que pasar hambre" (Adorno 1951: 162). Este y no otro es el movens de la Teoría Crítica.

\section{BIBLIOGRAFÍA}

ADORNO, Th. W. (1931): "Actualidad de la filosofía", en Escritos filosóficos tempranos, Obra completa 1, ed. de R. Tiedemann, trad. esp. de V. Gómez, Madrid, Akal, 2010, 297-314.

- (1951): Minima moralia. Reflexiones desde la vida dañada. Obra Completa 4, ed. de R. Tiedemann, trad. esp. de J. Chamorro, Madrid, Akal, 2004.

- (1953): "Anotaciones sobre Kafka" Crítica de la cultura y sociedad II, Volumen 2, Obra Completa 10/2, ed. de R. Tiedemann, trad. esp. de J. Navarro Pérez, Madrid, Akal, 2009, 223-250.

- (1955): "Sobre la relación entre sociología y psicología", en Escritos sociológicos I, Obra Completa 8, ed. de R. Tiedemann, trad. esp. de A. González Ruiz, Madrid, Akal, 39-78.

- (1959): “Qué significa elaborar el pasado?”, Crítica de la cultura y sociedad II, Volumen 2, Obra Completa 10/2, ed. de R. Tiedemann, trad. esp. de J. Navarro Pérez, Madrid, Akal, 2009, 489-503. 
- (1964/1965): Lehre von der Geschichte und von der Freiheit, in Nachgelassene Schriften. 4, Vorlesungen / vol. 13, Rolf Tiedemann (ed.). Frankfurt a.M.: Suhrkamp, 2001.

- (1965): "Sociedad", en Escritos sociológicos I, Obra Completa 8, ed. de R. Tiedemann, trad. esp. de A. González Ruiz, Madrid, Akal, 9-18.

- (1966a): Dialéctica Negativa, Obra Completa 6, ed. de R. Tiedemann, trad. esp. de A. Brotons Muñoz, Madrid, Akal, 2005.

- (1966b): "Postscriptum", en Escritos sociológicos I, Obra Completa 8, ed. de R. Tiedemann, trad. esp. de A. González Ruiz, Madrid, Akal, 79-85.

- (1967): "Educar después de Auschwitz", Crítica de la cultura y sociedad II, Volumen 2, Obra Completa 10/2, ed. de R. Tiedemann, trad. esp. de J. Navarro Pérez, Madrid, Akal, 2009, 599-614.

- (1968): "Anotaciones sobre el conflicto social hoy", en Escritos sociológicos I, Obra Completa 8, ed. de R. Tiedemann, trad. esp. de A. González Ruiz, Madrid, Akal, 165-182

- (1970): Teoría estética. Obra Completa 7, ed. de R. Tiedemann, trad. esp. de J. Navarro Pérez, Madrid, Akal, 2004.

- (1996): Introducción a la sociología (1968), comp. por Ch. Gödde, trad. de E. Rivera López, Barcelona, Gedisa.

- (1997): “Ob nach Auschwitz noch sich leben lasse". Ein philosophisches Lesebuch, ed. de R. Tiedemann. Frankfurt a.M.: Suhrkamp.

- (2003): "Graeculus (II): Notizen zu Philosophie und Gesellschaft 1943-1969", en Frankfurter Adorno Blätter VIII, ed. R. Tiedemann, München, text+kritik, 9-41.

ADORNO, Th. W. y MANN, Th. (2002): Briefwechsel 1943-1955, ed. de Ch. Gödde y Th. Sprecher, Frankfurt a.M.: Suhrkamp.

BENJAMIN, W. (1991): "Über den Begriff der Geschichte”, en: Gesammelte Schriften, Bd. I/2, ed. de R. Tiedemann y H. Schweppenhäuser. Frankfurt a.M.: Suhrkamp.

CABOT, M. (1997): El penós camí de la raó. Theodor W. Adorno i la crítica de la Modernitat, Palma de Mallorca, UIB.

- (2007) (ed.): El pensamiento de Th. W. Adorno. Balance y perspectivas. Palma, UIB. 
CLAUSSEN, D. (1988): "Nach Auschwitz. Ein Essay über die Aktualität Adornos", en Zivilisationsbruch. Denken nach Auschwitz, ed. de D. Diner, Frankfurt a.M.: Fischer, 54-68.

GÓMEZ, V (1998): El pensamiento estético de Theodor W. Adorno, Madrid, Cátedra.

HEITMANN, L. (2016/2017) "Acción comunicativa - Sistema - Crítica. Observaciones sobre la crítica sociológica del sistema en la teoría de la acción comunicativa de Jürgen Habermas", Constelaciones. Revista de Teoría Crítica, $\operatorname{vol} 8 / 9,46-81$.

HONNETH, A. (2011): Das Recht der Freiheit, Berlin, Suhrkamp.

JAEGGI, R. (2014): Kritik von Lebensformen, Berlin, Suhrkamp.

MAISO, J. (2010): Elementos para la reapropiación de Theodor W. Adorno. Salamanca, USAL.

- (2016): "Sobre la producción y la reproducción social de la frialdad", en J. A. Zamora, R. Mate y J. Maiso (eds.), Las víctimas como precio necesario, Madrid, Trotta, 51-70.

MEYERS, L. (2005): Absoluter Wert und allgemeiner Wille. Zur selbstdarstellung dialektischer Gesellschaftstheorie, Bielefled, transcript.

ROMERO, J. M. y J. A. ZAMORA (2020) (eds.): Crítica inmanente de la sociedad. Barcelona: Anthropos.

TIEDEMANN, R. (1997): “Nicht die Erste Philosophie sondern eine letzte", en Th. W. Adorno, $\mathrm{Ob}$ nach Auschwitz noch sich leben lasse". Ein philosophisches Lesebuch, ed. de R. Tiedemann. Frankfurt a.M.: Suhrkamp, 7-27.

- (2006): Rolf Tiedemann, "Kafka-Philologie, Kulturindustrielles und der Begriff Scham. Unordentliche Überlegungen zwischen Geschichts- und Moralphilosophie", en Philologie und Scham: und andere Texte von, über und für Rolf Tiedemann, ed. de E. Lenk u. G. Lolling, Wetzlar: Büchse de Pandora, 27-38.

- (2007): “Weißt Du, wie das wird?' Zur Aktualität von Adornos Theorie der Gesellschaft", en id. Niemandsland. Studien mit und über Adorno, München, text + kritik, 2007. 
- (2009): "Nicht die Erste Philosophie sondern eine letzte", en id., Mythos und Utopie. Aspekte der Adornoschen Philosophie, München 2009.

- (2011): "Lehrjahre mit Adorno (2010)", en id., Adorno und Benjamin noch einmal. Erinnerungen, Begleitworte, Polemiken, München, text+kritik.

ZAMORA, J. A. (2004): Theodor W. Adorno: pensar contra la barbarie. Madrid, Trotta.

- (2011): "Spanien [VII. Wirkung]", en Adorno-Handbuch. Leben - Werk Wirkung, ed. R. Klein, J. Kreuzer, St. Müller-Doohm, Stuttgart, MetzlerVerlag, 462-466.

ZAMORA, J. A., R. MATE y. J. MAISO (2016) (eds.), Las víctimas como precio necesario, Madrid, Trotta.

Recibido: 15 de octubre de 2019

Aceptado: 1 de noviembre de 2019

José A. Zamora es Investigador del Instituto de Filosofía del Consejo Superior de Investigaciones Científicas (Madrid). Sus investigaciones y publicaciones están dedicadas a los pensadores de la Teoría Crítica, a la industria cultural, a la relación entre religión y política y entre ciudadanía, interculturalidad e inmigración. Es autor, entre otras, de las siguientes publicaciones: Krise - Kritik Erinnerung. Ein politisch-theologischer Versuch über das Denken Adornos im Horizont der Krise der Moderne (1995), Th. W. Adorno: Pensar contra la barbarie (2004) y -como coordinador- Radicalizar la democracia (2001), Ciudadanía, multiculturalidad e inmigración (2003), Medios de comunicación: información, espectáculo y manipulación (2004) y (con R. Mate) Nuevas teologías políticas. Pablo de Tarso en la construcción de Occidente (2006). 